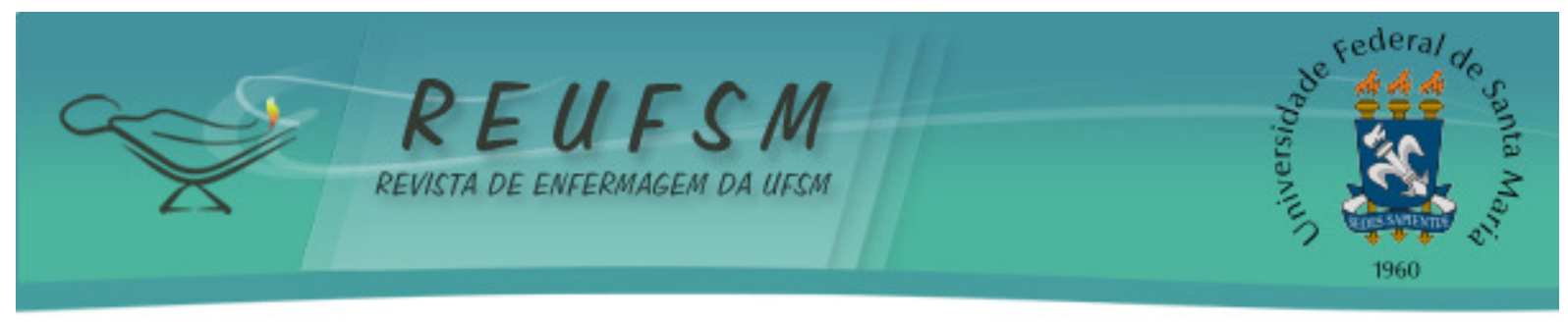

ARTIGO ORIGINAL

\title{
PLANO DE SAÚDE DOS MUNICÍPIOS DE UMA REGIONAL DE SAÚDE DO PARANÁ
}

\author{
HEALTH PLAN OF MUNICIPALITIES OF THE ONE REGIONAL HEALTH OF PARANA
}

PLAN DE SALUD DE LOS MUNICIPIOS DE UNA REGIONAL DE SALUD EN PARANÁ

\author{
Gleyce Mara Freitas ${ }^{1}$ \\ Tatiane Baratieri ${ }^{2}$ \\ Calíope Pilger ${ }^{3}$
}

RESUMO: Objetivo: analisar o conhecimento dos secretários de saúde acerca da elaboração do Plano Municipal de Saúde (PMS) dos municípios que compreendem a $5^{\mathrm{a}}$ Regional de Saúde do Paraná, quanto seu processo, dificuldades e relevância para a gestão municipal. Método: estudo quantitativo, exploratório; os dados foram coletados junto a oito secretários municipais de saúde, por meio de questionário semiestruturado autoaplicável, em outubro e novembro de 2011. Resultados: os pesquisados afirmaram ter o PMS, porém desconhecem a periodicidade de sua elaboração; 75\% contribuíram para a elaboração; 87,5\% nunca tiveram orientação/capacitação para elaborar o PMS, 50\% relataram que o plano foi elaborado por técnicos da secretaria municipal de saúde. Considerações finais: a elaboração do PMS dos municípios desta regional possui limitações, em virtude disso, há necessidade de atualização dos gestores, auxílio das esferas estaduais e federais, planejamento e envolvimento dos profissionais da saúde, visto que constitui um importante instrumento de gestão municipal.

DESCRITORES: Saúde pública; Gestão em saúde; Planejamento em saúde.

ABSTRACT: Objective: to analyse the knowledge of health Secretaries, about the preparation of the Municipal Health Plan (MHP) of municipalities that comprise the 5th Health Regional of Paraná, as its your process, difficulties and relevance to municipal management. Methods: a quantitative study, exploratory. The datas were collected with eight municipal health Secretariats, through self-administered semi-structured questionnaire, in October and November 2011. Results: the researcher claimed to have the MHP, but are unaware of the frequency of the preparation; $75 \%$ contributed to the development; $85,7 \%$ never have guidancel capacity building to elaborate the MHP; $50 \%$ reported that the plan was prepared by staff from the municipal health Secretary. Conclusion: the elaboration of MHP of the $5^{\circ}$ health regional municipalities has limitations, due to this, is necessary to update managers, receive aid from state and federal spheres, plan for and involve of health professionals, seen as, the MHP is an important instrument of municipal management.

DESCRIPTORS: Public health; Health management; Health planning.

RESUMEN: Objetivo: analizar el conocimiento de los secretarios de salud, acerca de la elaboración del Plan Municipal de Salud (PMS) de los municipios de la $5^{a}$ Regional de

\footnotetext{
${ }^{1}$ Enfermeira da Secretaria de Saúde do município de Rio Bonito do Iguaçu - PR. Especialista em Urgência e Emergência pela PUC Maringá e Especialista em Gestão em Saúde pela Universidade Estadual do Centro Oeste UNICENTRO. E-mail: gleyce_mara@yahoo.com.br.

${ }^{2}$ Enfermeira. Mestre em Enfermagem pela Universidade Estadual de Maringá - UEM. Docente do departamento de enfermagem da Universidade Estadual do Centro Oeste - UNICENTRO. E-mail: baratieri.tatiane@gmail.com. ${ }^{3}$ Enfermeira. Mestre em Enfermagem pela Universidade Estadual de Maringá - UEM. Doutoranda da Escola de Enfermagem de Ribeirão Preto da Universidade de São Paulo - USP. E-mail: caliopepilger@usp.br.
} 


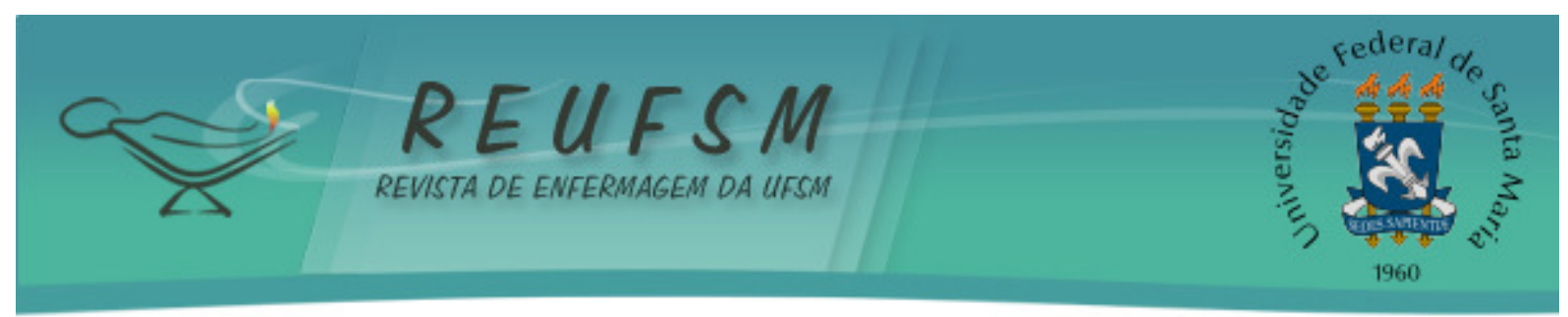

Salud del Paraná, concerniente a su proceso, las dificultades y relevancia para la gestión municipal. Método: estudio cuantitativo, exploratorio; los datos fueron recolectados con ocho secretarios, a través del cuestionario semiestructurado auto aplicable, en octubre y noviembre de 2011. Resultados: los investigados afirmaron tener el PMS, pero desconocen la periodicidad de su elaboración; el 75\% contribuyeron para la elaboración; el $87,5 \%$ nunca tuvieron orientación para elaborar el PMS, el 50\% fue elaborado por técnicos de la secretaría de salud municipal. Conclusión: la elaboración de este PMS posee limitaciones, por lo tanto hay necesidad de actualización de los gestores, auxilio de las esferas estatal y federal, planeamiento y envolvimiento de los profesionales de salud visto que constituye un importante instrumento de gestión municipal.

DESCRIPTORS: Salud pública; Gestión en salud; Planificación em salud.

\section{INTRODUÇÃO}

A Constituição Federal de 1988 reconfigurou a concepção de saúde pública passando essa a ser um direito do cidadão e dever do Estado exercido por meio do Sistema Único de Saúde (SUS), que visa à descentralização político-administrativa, a integralidade e a participação social. Essa configuração do SUS traduz-se em um desafio para a gestão pública, pois permeia os campos da saúde e política, envolvendo interesses coletivos e individuais. ${ }^{1}$ As diretrizes do SUS estabeleceram no contexto da municipalidade instrumentos que possibilitassem o planejamento local das ações de saúde, visando dar a possibilidade de organização aos municípios. ${ }^{2}$

Nesse âmbito, destaca-se que o planejamento é percebido como uma junção de práticas que possibilitam a gestão por compromissos com um modelo de gestão negociado, de ajustamento mútuo e comunicativo. Nessas bases, o planejamento é um instrumento organizacional, uma forma de desenhar e acompanhar a execução de estratégias destinadas a operacionalizar decisões institucionais, uma ferramenta para condução da ação, porém, mediada e subordinada à cultura das organizações. ${ }^{3}$

É de responsabilidade das instituições componentes do SUS, por esfera de governo as atividades de planejamento, tanto do ponto de vista da gestão como quanto no arcabouço jurídico. Portanto, o planejamento e seus produtos são definidos como funções da União, dos Estados e dos Municípios de acordo com as regras jurídicas do sistema. ${ }^{3}$

Assim, no presente trabalho, destaca-se a prática do planejamento municipal, que hoje se torna uma efetivação da proposta de descentralização do SUS orientada a partir da Norma Operacional Básica de 1996 e as Normas Operacionais de Assistência a Saúde de 2001 e 2002, que constituem documentos importantes na concretização da descentralização por incentivar a reorganização das diferentes esferas de governo na gestão da saúde. ${ }^{4}$

A utilização de instrumentos de planejamento nas três esferas de governo do SUS é tema amplamente visado pelo Ministério da Saúde (MS), sendo estabelecido no ano de 2006 uma política específica para este assunto, por meio da Portaria $\mathrm{n}^{\circ} 3.085$, intitulada PlanejaSUS. ${ }^{5}$ Porém, esses instrumentos com principal destaque ao Plano de Saúde, citado desde a Lei 8.080 , de 19 de setembro de 1990, encontram grandes entraves na esfera municipal, principalmente em municípios de pequeno porte.

Nesta perspectiva, foram determinados os instrumentos básicos que comporiam o PlanejaSUS que são: o Plano de Saúde; a Programação Anual de Saúde; e o Relatório Anual de Gestão. Destes, merece destaque o Plano de Saúde, o qual se apresenta como o instrumento que, por meio de uma análise situacional, contempla os objetivos e os resultados que deverão ser alcançados em um período de quatro anos, tendo sua estruturação com objetivos, diretrizes e metas. ${ }^{6}$ 


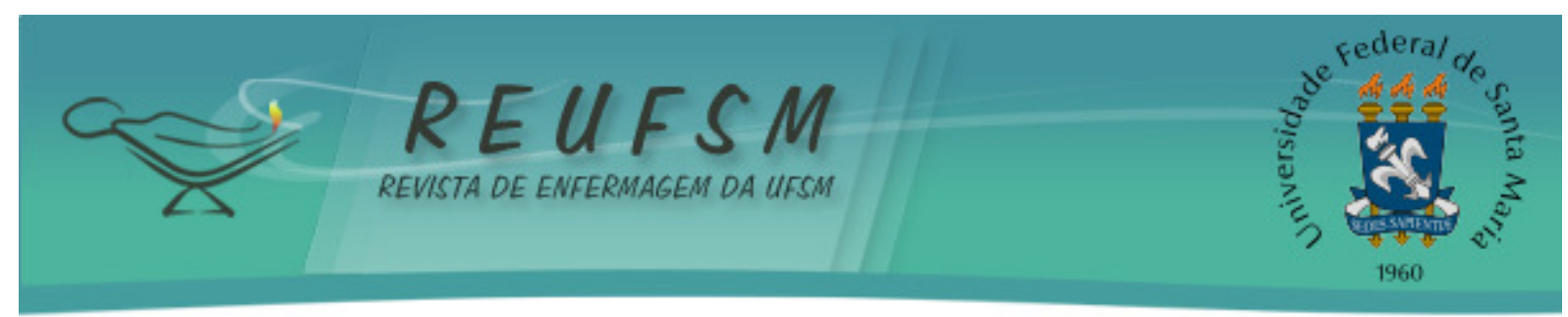

A elaboração do Plano de Saúde pode ser percebida em dois momentos, que são a análise situacional, a formulação dos objetivos, diretrizes e metas. São indicados três eixos norteadores, que estão em conformidade com a Portaria $n^{\circ} 3.332$ de 2006 , em seu Art. $5^{\circ}$, são eles: a condição de saúde da população através da vigilância em saúde, atenção básica, assistência ambulatorial especializada, assistência hospitalar, assistência de urgência e emergência e assistência farmacêutica; os determinantes e condicionantes de saúde e a gestão em saúde com o planejamento, a descentralização, a regionalização, o financiamento, a participação social, a gestão do trabalho em saúde, a educação em saúde, a informação em saúde e a infraestrutura. ${ }^{7}$

As Secretarias Municipais de Saúde, que são responsáveis pela elaboração do Plano de Saúde em sua esfera, encontram-se, por vezes, despreparadas para o cumprimento e efetiva utilização deste instrumento. Isso ocorre, geralmente, devido à falta de conhecimento e preparo para a realização, a cobrança e orientação inexistente por parte de outras esferas, além do desconhecimento de sua importância para a gestão da saúde municipal. Os estudos encontrados geralmente abordam o planejamento relacionado à esfera nacional ou estadual, e quando da esfera municipal, em cidades de grande porte como capitais.

O Plano de Saúde trata-se de um instrumento básico para nortear a gestão e assim poder programar as ações dos serviços de saúde, devendo ser realizado por todos os municípios e mantendo atualizado e em consonância com o Plano Plurianual, Lei de Diretriz Orçamentária e Lei Orçamentária Anual. ${ }^{8}$

Sua importância se dá ao passo que apresenta uma análise situacional da saúde do município estudado, com as intenções e os resultados a serem alcançados, contendo objetivos, diretrizes e metas. Devido a esse contexto, surgiu o interesse em realizar essa pesquisa visando analisar o conhecimento dos secretários de saúde dos municípios da $5^{\circ}$ Regional de Saúde do Paraná acerca da elaboração do Plano Municipal de Saúde, quanto ao seu processo, dificuldades e sua relevância para a gestão municipal. Visto que ao observar a existência do Plano de Saúde nos municípios e investigar o conhecimento dos gestores, auxilia o planejamento das futuras ações municipais e regionais de saúde, além de ser subsídio para a gestão municipal de saúde.

\section{MÉTODO}

0 presente estudo teve abordagem quantitativa e trata-se de uma pesquisa exploratória, pois objetivou a investigação da realidade dos municípios quanto a utilização do Plano de Saúde, devido a pequena quantidade de pesquisas sobre o tema. A pesquisa também teve caráter descritivo porque tentou descrever as formas de utilização do Plano de Saúde pelos municípios.

O estudo foi realizado no âmbito da $5^{a}$ Regional de Saúde do Estado do Paraná, que tem sua sede no município de Guarapuava, localizada na região Centro-Sul do estado, a qual atende e é referência para 20 municípios.

Esses municípios juntos, segundo dados do Censo $2010^{9}$, possuem uma população de 441.108 habitantes, sendo $75 \%$ destes municípios de pequeno porte, com população inferior a 20 mil habitantes. Uma das características, que é comum a grande maioria destes municípios é possuir sua economia baseada predominantemente na agricultura.

Outro ponto comum é o Índice de Desenvolvimento Humano (IDH) que apresenta baixo na região estudada, mais da metade dos municípios que compreendem a $5^{a}$ Regional de Saúde do Paraná encontram-se entre as últimas 100 colocações, comparados aos outros 399 municípios do estado. A média entre os 20 municípios, os quais os participantes do estudo são gestores, chega a um IDH de 0,706, índice considerado médio, porém se 


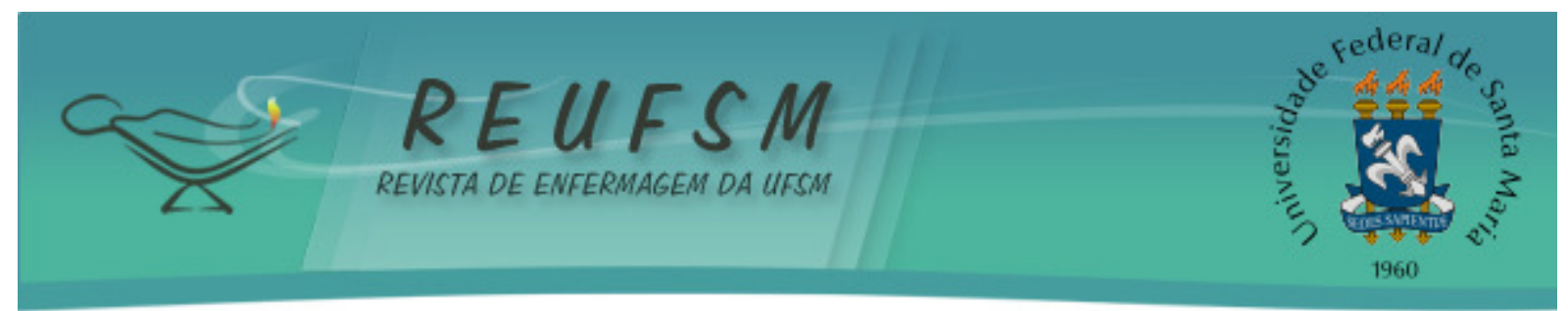

comparado com o do estado do Paraná $(0,787)$ e com região sul do país $(0,807)$ considerase baixo. ${ }^{10}$

Os sujeitos da pesquisa foram os Secretários Municipais de Saúde dos municípios que compõem a $5^{\text {a }}$ Regional de Saúde possibilitando assim ter uma visão completa da forma de utilização do Plano de Saúde por estes gestores. Eles foram convidados por telefone pelas pesquisadoras para responder o questionário que foi aplicado pessoalmente.

A pesquisa foi realizada por meio de um questionário semiestruturado, autoaplicável, elaborado pelas autoras da pesquisa, contendo questões abertas e fechadas, aplicado nas reuniões da Comissão Intergestores Bipartite (CIB) Regional, que acontecem mensalmente, no município de Guarapuava/PR.

A coleta dos dados foi realizada nas reuniões dos meses outubro e novembro de 2011. Os critérios de inclusão do estudo são: estar no cargo de gestor municipal de saúde dos municípios da $5^{a}$ Regional de Saúde do Paraná, estar presente nas reuniões dos meses de outubro e novembro de 2011. Dos 20 Secretários de Saúde, o questionário foi entregue a 13 gestores, ou seja, $65 \%$ do total de Secretários Municipais de Saúde pertencentes a $5^{\text {a }}$ Regional de Saúde, os demais não compareceram às reuniões da CIB Regional, portanto, não puderam integrar a pesquisa.

Os dados foram descritos em planilha do programa Excel, com dupla digitação. Para as questões abertas do questionário, as mesmas foram categorizadas e transformadas em variáveis. A análise dos mesmos foi realizada por meio de estatística descritiva, com frequência simples e porcentagem.

Essa pesquisa foi desenvolvida levando em conta a resolução $\mathrm{n}^{\circ} 196$ de 10 de outubro de 1996 do Conselho Nacional de Saúde, sobre diretrizes e normas reguladoras de pesquisas envolvendo seres humanos, com parecer favorável do Comitê de Ética em Pesquisa com Seres Humanos da Universidade Estadual do Centro-Oeste - UNICENTRO, de $n^{\circ} 208 / 2011$.

\section{RESULTADOS E DISCUSSÃO}

De posse dos resultados encontrou-se que dos 13 gestores que estavam presentes na reunião, apenas oito gestores $(66,7 \%)$ responderam ao questionário de forma integral, sendo a análise realizada através destas respostas. Com relação aos cinco participantes que não responderam ao questionário de forma integral, três $(23 \%)$ não souberam responder e dois $(15,3 \%)$ receberam o questionário e não responderam.

Em virtude da não adesão de cinco gestores na pesquisa, devido à falta de conhecimento em responder o instrumento e receber o mesmo e devolvê-lo em branco, percebe-se a dificuldade e ausência de conhecimento relacionado a assuntos que são inerentes ao cargo que ocupam.

A literatura aponta que um dos grandes problemas que afetam a função dos gestores é a falta de profissionalização, aliada a grande rotatividade e a falta de preparo dos profissionais escolhidos para exercerem esses cargos, ${ }^{3}$ o que pode justificar em parte os resultados do estudo.

Essa falta de continuidade administrativa também pode ser atribuída a forças políticas que influenciam a ocupação desses cargos, o que leva a pensar na construção de formatos institucionais que diminuam essa vulnerabilidade do sistema de saúde, garantindo certa proteção às turbulências da vida político-partidária, possibilitando a efetividade, eficiência e eficácia da gestão. ${ }^{11}$

Com relação aos gestores que responderam ao questionário podemos observar as variáveis que dizem respeito à organização e implementação do Plano de Saúde (Tabela 1). 


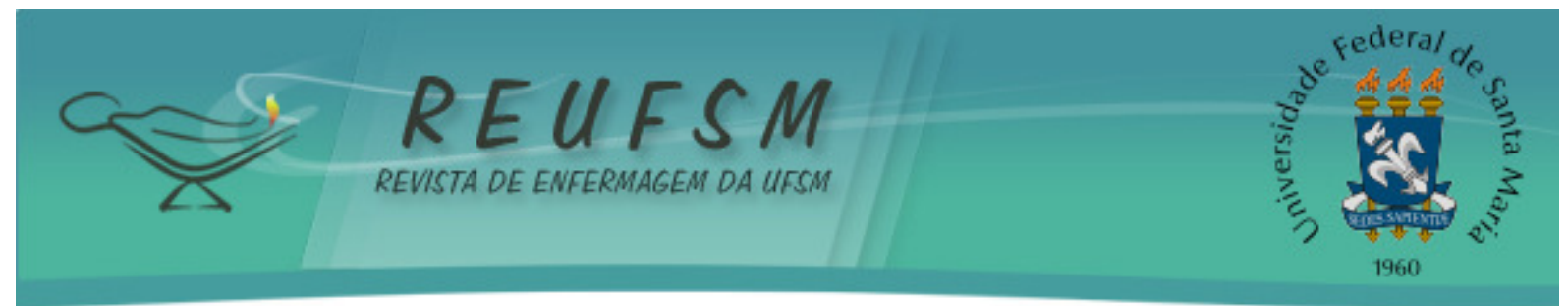

Tabela 1 - Distribuição das variáveis relacionadas à organização e implementação do Plano de Saúde da $5^{\text {a }}$ Regional de Saúde, de acordo com os gestores municipais, Guarapuava/PR, 2011.

\begin{tabular}{lcc}
\hline \multicolumn{1}{c}{ Variáveis } & N & \% \\
\hline Possui Plano de Saúde & 8 & 100 \\
Sim & 0 & 0 \\
Não & & 12,5 \\
Período de Vigência do Plano & 1 & 25,0 \\
1 ano & 2 & 62,5 \\
3 anos & 5 & \\
4 anos & 0 & 75 \\
Contribuiu para realização & & 25 \\
Sim & 6 & 100 \\
Não & 2 & 0 \\
Simsidera o Plano importante & & 75 \\
Não & 8 & 25 \\
Utiliza em suas atividades & 0 & 12,5 \\
Sim & & 87,5 \\
Não & 6 & 12,5 \\
Participou de capacitação & 2 & 87,5 \\
Nim & 1 & \\
Recebeu orientação do Estado ou Nação & 7 & \\
Sim & 1 & \\
Não & 7 & \\
\hline
\end{tabular}

Fonte: Dados das pesquisadoras, 2011.

Os resultados apontam que em todos os municípios estudados há o Plano de Saúde, dado esse, contrário a estudo realizado em municípios da Paraíba, que dos 15 municípios pesquisados, 11 não possuíam PMS. ${ }^{12}$ Entretanto, quando solicitado o período de vigência destes, constatou-se divergência nas respostas. Cinco gestores $(62,5 \%)$ responderam que seus Planos de Saúde têm seu período de vigência de 2010 a 2013, porém dois $(25 \%)$ responderam que o período é de dois anos e o outro $(12,5 \%)$ respondeu que o Plano é realizado anualmente.

Com base no exposto, nota-se que os gestores desconhecem sobre o processo de organização e vigência do Plano de Saúde. Ressalta-se que o período de vigência do Plano de Saúde também é regulamentado pela Portaria $n^{\circ} 3.332$, de 28 de dezembro de 2006, a qual pontua que o Plano de Saúde vem sendo apresentado como o instrumento, que por meio de uma análise situacional, contempla os objetivos, diretrizes, metas e os resultados que deverão ser alcançados em um período de quatro anos. ${ }^{6-7}$

A análise situacional de saúde do município é realizada para que as metas do PMS sejam elaboradas conforme a realidade local, tendo em vista que após a elaboração do PMS por um período determinado, esse deve ser continuamente monitorado e avaliado, no intuito de planejar e replanejar as diversas ações e serviços de saúde. ${ }^{13}$

Outro ponto abordado na pesquisa foi à contribuição do gestor para elaboração do Plano de Saúde, pôde-se perceber que a maioria (75\%) contribuiu para elaboração. Assim, os gestores que têm conhecimento sobre esse instrumento de planejamento têm a capacidade de contribuir para sua elaboração e execução, mostrando o quanto é importante que os gestores estejam orientados e capacitados para exercerem suas funções. 


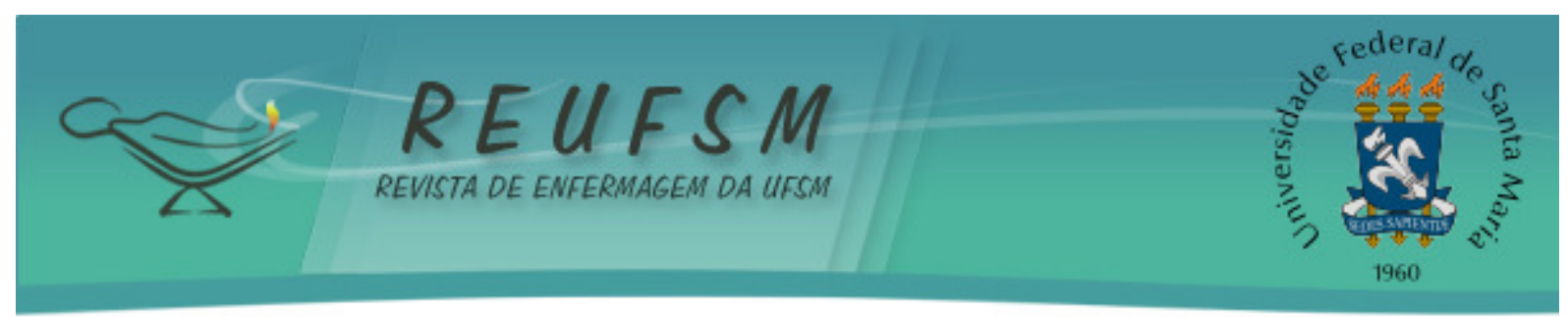

Há muito tempo, percebem-se discussões a respeito da "profissionalização da gestão do SUS", porém, não existindo ainda ações concretas a respeito da criação da carreira de "gestor do SUS", o que possibilitaria a valorização dos profissionais envolvidos com estas atividades. ${ }^{11}$

Com relação à importância do Plano de Saúde, 100\% dos gestores relataram ser um instrumento importante para seu trabalho. Este fato leva a constatar que, embora os gestores não conheçam profundamente os instrumentos de planejamento todos entendem a sua importância e necessidade.

$\mathrm{Na}$ Saúde Pública, por mais que alguns estudos tentem afastar a razão dos instrumentos de planejamento através da introdução de aspectos da subjetividade, o que se almeja, somente pode ser conseguido, se os gestores entenderem que o planejamento não se resume a si mesmo, mas sim em um elemento de mediação entre o idealizado e o objetivo alcançado. ${ }^{14}$

A respeito da utilização do Plano de Saúde, a maior parte dos entrevistados (75\%) disse que o utilizam. 0 fato de nem todos os gestores relatarem a utilização do PMS na prática pode estar diretamente relacionada a não participação desses na elaboração do mesmo, além disso, a existência do PMS em muitas situações está vinculada a transferência de recursos financeiros aos municípios, fazendo com que muitos, elaborem o plano em decorrência de uma exigência formal. ${ }^{12}$

Corroborando com o exposto acima, estudo realizado no município de Salvador revela que os gestores citam a burocratização do sistema de planejamento municipal, sendo que esses instrumentos são realizados em sua maioria a fim de cumprir exigências legais, visando o repasse de recursos federais, sem o intuito de auxiliar o processo de gestão do município. ${ }^{15}$

Por outro lado, é válido destacar que o gestor é o responsável pela organização, estruturação e funcionamento do setor de saúde e que a área de planejamento é fundamental para a elaboração dos instrumentos que expressam os resultados decorrentes do processo de planejamento. ${ }^{4}$

Com relação a treinamentos, palestras ou capacitações direcionadas aos gestores a fim de esclarecer sobre o Plano de Saúde $(87,5 \%)$ dos pesquisados falaram que nunca participaram e apenas um (12,5\%) relatou ter participado de um momento de orientação. Esse é um dado alarmante, tendo em vista que para a boa execução do planejamento municipal se faz necessário que o gestor tenha conhecimento e esteja capacitado para isso. 0 resultado encontrado também pode justificar a não participação e não utilização do Plano por parte dos gestores municipais.

Capacitar gestores municipais para a efetivação do SUS significa acrescer sua governabilidade por meio do aumento da capacidade de governo, com a qual eles poderão formular projetos de governo capazes de melhor enfrentamento dos problemas detectados. ${ }^{11}$

A implementação de ações de educação no trabalho constitui-se em um dos mais sérios desafios para os gestores/trabalhadores dos serviços de saúde. Considera-se a educação um fenômeno social e universal, bem como uma atividade necessária para o desenvolvimento humano. No entanto, para que isso aconteça, necessita-se investir na contínua educação dos sujeitos, ajudando-os no desenvolvimento de suas capacidades, para que possam tornar-se mais ativos nas instâncias sociais em que convivem. ${ }^{12}$

$\mathrm{Na}$ mesma direção, quando questionados sobre o recebimento de alguma orientação de outra esfera de governo quanto à elaboração do Plano de Saúde apenas um $(12,5 \%)$ respondeu que sim.

Com relação às competências das esferas de governo não se chega a estabelecer um consenso a respeito das suas responsabilidades e funções, gerando por vezes conflitos 


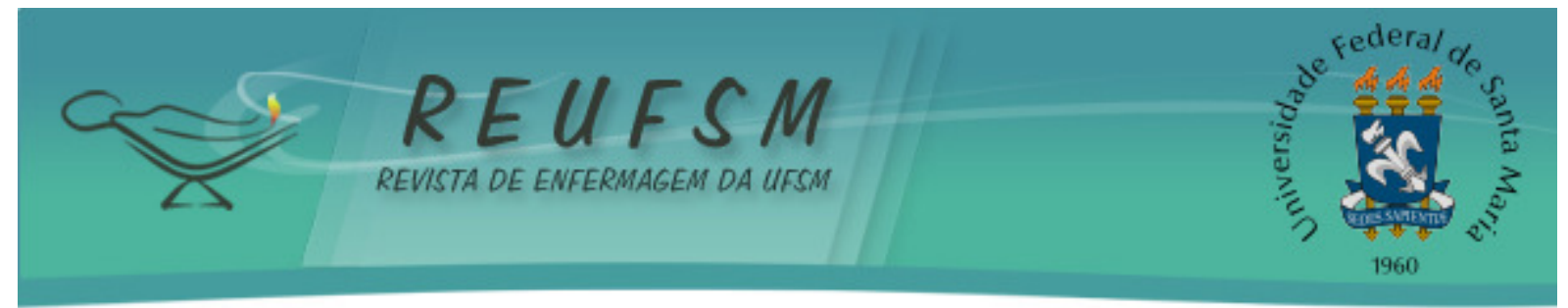

entre as várias instituições, federais, estaduais e municipais, que vem sendo mediada através das pactuações. Acredita-se que essa dificuldade de comunicação entre as três esferas se dê pela heterogeneidade e pela contaminação das relações intergovernamentais por interesse político-partidários. ${ }^{11}$

Ainda na perspectiva da elaboração do Plano de Saúde pelos municípios que compõem esta Regional de Saúde, foi questionado aos gestores quem foi ou quais foram às pessoas responsáveis pela sua elaboração, e se essas pessoas foram capacitadas para este fim. Os resultados a estes questionamentos estão evidenciados na Tabela 2.

Tabela 2 - Distribuição das variáveis relacionadas às pessoas que realizaram e se foram capacitadas para realização do Plano de Saúde da $5^{\text {a }}$ Regional de Saúde, Guarapuava/PR, 2011.

\begin{tabular}{lcc}
\multicolumn{1}{c}{ Variáveis } & $\mathbf{n}^{*}$ & $\%$ \\
\hline Responsáveis pela elaboração & & 50 \\
Técnicos da SMS & 4 & 25 \\
Secretário Municipal de Saúde & 2 & 25 \\
Conselho Municipal de Saúde & 2 & 12,5 \\
Enfermeiras & 1 & 12,5 \\
Todos os funcionários & 1 & 12,5 \\
Receberam treinamento & & 87,5 \\
Sim & 1 & \\
Não & 7 & \\
\hline
\end{tabular}

Fonte: Dados das pesquisadoras,

* Admite mais de uma resposta.

No que diz respeito às pessoas responsáveis pela elaboração de Plano de Saúde foram citados os técnicos da Secretaria Municipal de Saúde $(50 \%)$, porém sem a especificação de quais seriam estes técnicos, alguns gestores pontuaram que participaram da elaboração do Plano (25\%) o Conselho Municipal de Saúde também foi citado como colaborador na estruturação do Plano $(25 \%)$ um $(12,5 \%)$ gestor citou as enfermeiras, e um $(12,5 \%)$ respondeu dizendo que todos os funcionários participaram da elaboração do Plano de Saúde, ou seja, foram percebidas respostas genéricas, que não dizem de forma clara quem realmente elaborou o Plano de Saúde.

Esses dados outra vez nos mostram a falta de envolvimento de alguns gestores, assim como de profissionais preparados para tamanha responsabilidade. Nesse ponto, pode-se reforçar resultados discutidos anteriormente, de que a elaboração do Plano de Saúde é necessária para cumprimento de determinações legais, sendo essa atividade repassada para algumas pessoas, muitas vezes sem antes discutir sobre sua habilitação para executar determinadas tarefas.

Destaca-se a importância para o planejamento, do envolvimento dos profissionais da saúde, visto que seriam eles os responsáveis pelo alcance de metas propostas, a não participação destes profissionais pode levar a construção de um planejamento distanciado dos resultados alcançados. Sendo este planejamento elaborado de forma a satisfazer exigências de outras esferas, ao invés de ser tratado como um verdadeiro instrumento para a implementação da política de saúde ou como base para alocação de recursos. ${ }^{6}$

Nessa perspectiva, torna-se necessário avanços no que diz respeito à implementação de planos de cargos, carreiras e salários, a serem efetivados pelo âmbito federal, estadual e municipal, estimulando a realização de concursos públicos, que levam em conta a qualificação e a experiência dos profissionais. ${ }^{16}$

Um dado importante foi à colocação da participação do Conselho Municipal de Saúde, visto que este tem papel importante e tem sua participação garantida por Lei $\mathrm{n}^{\circ}$ 8.142 de 1990, sendo dever das distintas esferas de governo apoiar os conselhos as 


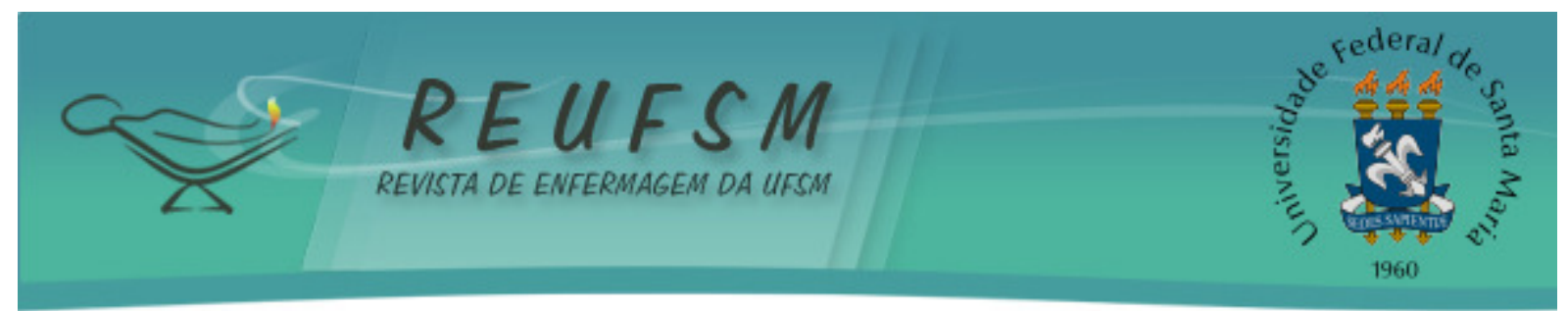

conferências de saúde, propiciando seu fortalecimento, para que seus membros possam exercer plenamente seus papeis, inclusive na participação do planejamento local. ${ }^{4}$

A literatura destaca que a elaboração do PMS ocorre pela equipe da gestão municipal de saúde, não contando com a participação da sociedade, o que vai contra o princípio organizativo do SUS de participação social, o que dificulta a elaboração de diretrizes e metas que se objetiva com as ações em saúde a serem desenvolvidas no período de vigência do PMS elaborado. ${ }^{12-13}$

Quando questionados quanto à participação dos profissionais que elaboraram o Plano de Saúde, em capacitações, palestras ou treinamentos sobre o assunto, 87,5\% afirmaram que estes funcionários não participaram de nenhum momento de orientação e apenas um $(12,5 \%)$ relatou que receberam treinamento para este fim.

A execução de atividades importantes, como o caso da elaboração de um Plano de Saúde parece ser realizada de maneira empírica, por meio da disponibilidade e do empenho das pessoas designadas a este papel, em buscar informações por si próprias, que baseiem a construção de tal instrumento, sem que haja para isso, uma prévia orientação sobre no que consiste um Plano de Saúde, onde buscar informações para sua elaboração e sobre a sua importância para a gestão municipal.

Em outro estudo realizado, em que um questionamento semelhante foi feito constatou-se que a orientação para elaboração do Plano de Saúde deve ser oferecida a todos os municípios que dela necessitarem, sendo que o estado é o responsável em dar maior apoio aos municípios que não disponham de suporte técnico. Também foi verificado que aquele profissional que possui algum grau de capacitação torna-se mais consciente da importância do Plano de Saúde para a gestão. ${ }^{17}$

Atrelado à questão de quem elaborou o Plano de Saúde foi perguntado onde estes técnicos buscaram estas informações. Estes resultados são apresentados na Tabela 3.

Tabela 3 - Distribuição de locais onde os técnicos buscam informações para estruturação do Plano de Saúde da $5^{\text {a }}$ Regional de Saúde, Guarapuava/PR, 2011.

\begin{tabular}{lcc}
\hline \multicolumn{1}{c}{ Variáveis } & $\mathbf{N}^{*}$ & $\%$ \\
\hline Sistemas de informação & 2 & 25 \\
Sitio do Ministério da Saúde & 4 & 50 \\
Sitio da Secretaria Estadual de Saúde de Santa & 1 & 12,5 \\
Catarina & 5 & 62,5 \\
\hline
\end{tabular}

Fonte: Dados das pesquisadoras, 2011.

* Admite mais de uma resposta.

De acordo com a tabela 3, não há uma uniformidade na busca de informações para elaboração do Plano de Saúde, sendo que cada município adquire essas informações onde julga mais acessível, o que se percebem em comum é que todos utilizam a internet, quer seja através de sítios do Ministério da Saúde (50\%) ou da Secretaria Estadual de Saúde de Santa Catarina (12,5\%), quer seja por sistemas de informação (25\%) que são executados através da internet, ou através de modelos de outros municípios $(62,5 \%)$, que também são verificados por meio da internet.

Apenas metade dos gestores cita os sítios do Ministério da Saúde, o que evidência o pequeno aproveitamento de materiais tão importantes que são criados com o intuito de instrumentalizar os municípios e os estados na elaboração dos instrumentos de planejamento, entre eles o Plano da Saúde. Observa-se que nenhum gestor citou as publicações do Sistema de Planejamento no SUS (PlanejaSUS), que trazem de forma detalhada os componentes necessários para estruturação do Plano de Saúde. Outro dado 


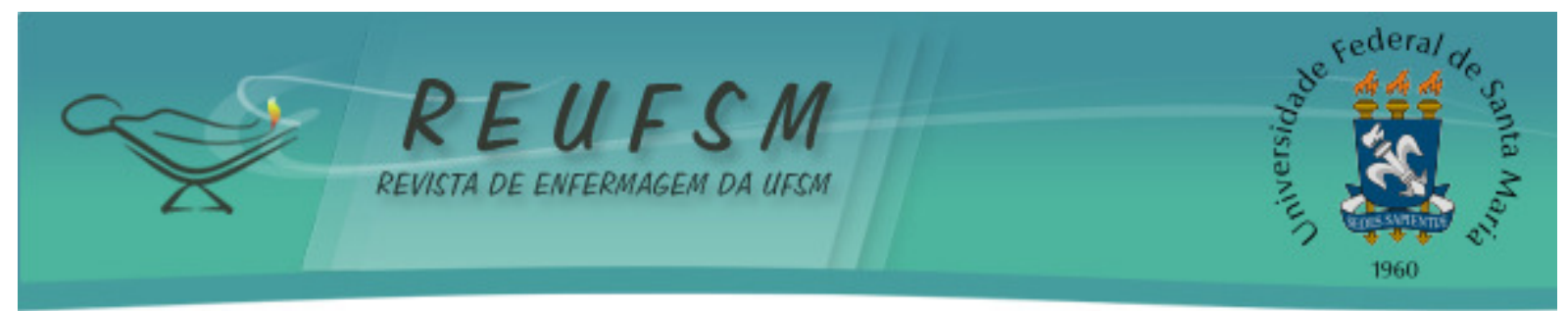

importante se refere ao relato de um dos participantes que busca informações para a estruturação do PMS no sítio da Secretaria Estadual de Saúde do estado de Santa Catarina, não do estado do Paraná.

Acredita-se que isso é justificado pelo fato, de que no momento da elaboração do Plano de Saúde, os responsáveis não terem utilizado, ou não terem conhecimento destas publicações, ou também pelo desconhecimento dos gestores a respeito dos meios utilizados para elaboração do Plano de Saúde, merecendo destaque a falta de apoio por parte das esferas estadual e federal evidenciada no presente estudo.

O planejamento é ferramenta de gestão das três esferas de governo no âmbito do SUS, o qual viabiliza definir objetivos e a organização das ações a serem desenvolvidas. Esse instrumento facilita o acompanhamento, a fiscalização, o controle dos gastos e a avaliação dos resultados obtidos. ${ }^{18}$

É de suma importância destacar que o planejamento é de responsabilidade dos municípios, estados e federação, e reflete a necessidade de informações atualizadas e constantes para viabilizar a reflexão dos gestores sobre os modos de operar as atividades de planejamento, e possa os auxiliar na tomada de decisão, de acordo com as necessidades do SUS. ${ }^{18}$

\section{CONSIDERAÇÕES FINAIS}

Com base no exposto, destaca-se que os objetivos desta pesquisa foram alcançados, visto que pretendeu analisar o conhecimento dos secretários de saúde, acerca da elaboração do PMS. O estudo revelou contradições, como quando os gestores são questionados sobre sua participação na elaboração e utilização do PMS em suas atividades, em que mais da metade relata respostas positivas, porém quando questionados sobre o responsável pela elaboração e de que forma estas pessoas construíram o respectivo plano, as informações não são claras, evidenciando um desconhecimento sobre o assunto e a não sistematização das ações conforme preconiza o Ministério da Saúde.

Os dados apontaram para o desconhecimento sobre o PMS por parte de alguns gestores, visto que, cinco de um total de treze participantes não responderam ao questionário. Assim, a análise dos dados sugere a necessidade de atualização, acompanhamento e assessoramento por parte da esfera estadual e federal destes profissionais e de toda equipe gestora do município, além de valorizar a qualificação, experiência e conhecimento prévio ao atribuir-se cargo de gestão municipal.

Como limitação do estudo, aponta-se para o pequeno número de participantes no estudo, permitindo caracterizar apenas uma pequena parcela de municípios no âmbito da $5^{a}$ Regional de Saúde do Paraná, contudo, essa limitação não impediu que se fosse alcançado o objetivo proposto.

0 presente estudo serve de subsídio para alertar as esferas municipal, estadual e federal sobre a importância do uso do PMS como ferramenta de gestão, especialmente no que tange ao planejamento das ações de saúde municipal. Aponta-se a necessidade de estudos mais aprofundados sobre o tema, a fim de conhecer com mais propriedade a realidade dos municípios, possibilitando formular políticas e ações pertinentes em todas as esferas de governo.

\section{REFERÊNCIAS}

1. Pessalacia JDR, Oliveira VC, Guimarães EAA. Equidade de assistência à saúde no Brasil: uma análise segundo o princípio bioético da justiça. R Enferm Cent O Min [Internet]. 2011 


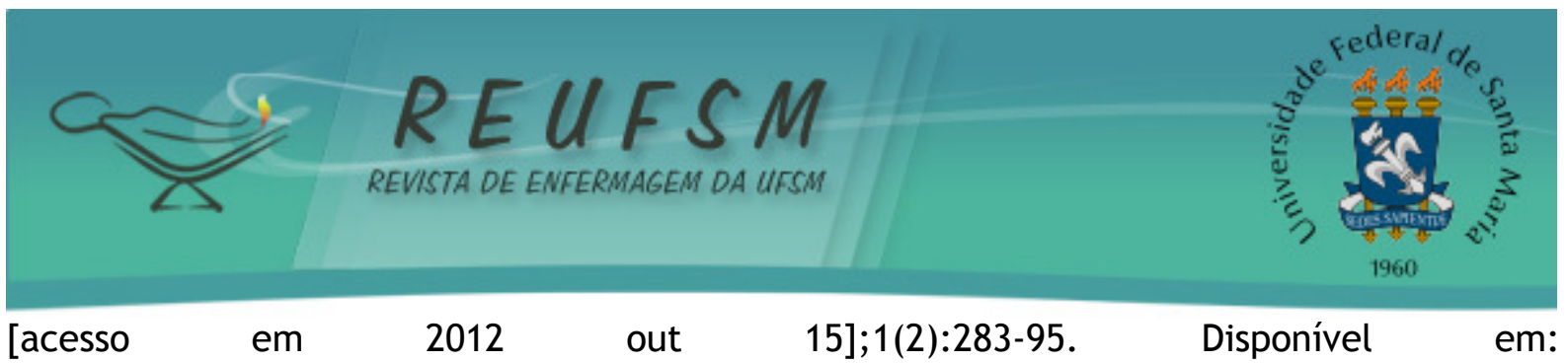

http://www.seer.ufsj.edu.br/index.php/recom/article/view/38/152.

2. Jesus WLA. Ressignificação do planejamento no campo da saúde coletiva: desafios teóricos e busca de novos caminhos [dissertação]. Feira de Santana (BA): Universidade Estadual de Feira de Santana; 2006. 235 p.

3. Rocha AARM. O planejamento no cotidiano de uma instituição hipercomplexa: o caso da SES/Sergipe [tese]. Salvador (BA): Universidade Federal da Bahia, Instituto de Saúde Coletiva; 2008. 156 p.

4. Barreta IQ, Lacerda JT, Calvo MCM. Modelo de avaliação de gestão municipal para o planejamento em saúde. Cad Saúde Pública [Internet]. 2011 [acesso em 2012 nov 05];27(11): 2143-54. Disponível em: http://www.scielo.br/pdf/csp/v27n11/08.pdf.

5. Brasil. Ministério da Saúde. Portaria $n^{\circ} 3.085$, de $1^{\circ}$ de dezembro de 2006 . Regulamenta o sistema de planejamento do SUS. 2006 [acesso em 2011 ago 15]. Disponível em: http://bvsms.saude.gov.br/bvs/saudelegis/gm/2006/prt3085_01_12_2006.html.

6. Vieira FS. Avanços e desafios do planejamento no Sistema Único de Saúde. Ciênc Saúde Coletiva [Internet] 2009 [acesso em 2012 out 28];14(Supl1):1565-77. Disponível em: http: //www.scielo.br/pdf/csc/v14s1/a30v14s1.pdf.

7. Brasil. Ministério da Saúde. Sistema de Planejamento do SUS: uma construção coletiva. $2^{\mathrm{a}}$ ed. Brasília (DF); 2009. (Série Cadernos de planejamento, 2).

8. Brasil. Ministério da Saúde. Portaria $n^{\circ} 3.332$, de 28 de dezembro de 2006. Aprova orientações gerais relativas aos instrumentos do Sistema de Planejamento do SUS. 2006 [acesso em 2011 jun 10]. Disponível em: http://bvsms.saude.gov.br/bvs/saudelegis/gm/2006/prt3332_28_12_2006.html.

9. IBGE. Instituto Brasileiro de Geografia e Estatística. Sinopse do Censo Demográfico 2010. Rio de Janeiro; 2010 [acesso em 2011 ago 15]. Disponível em: http://www.ibge.gov.br/home/estatistica/populacao/censo2010/sinopse/sinopse_tab_pdf.shtm 10. IPARDES. Instituto Paranaense de Desenvolvimento Econômico e Social. Índice de Desenvolvimento Municipal 2011. Curitiba (PR); 2011 [acesso em 2011 ago 15]. Disponível em: http://www.ipardes.pr.gov.br/modules/conteudo/conteudo.php?conteudo=99.

11. Paim JS, Teixeira CF. Configuração institucional e gestão do Sistema Único de Saúde: problemas e desafios. Ciênc Saúde Coletiva [Internet]. 2007 [acesso em 2012 out 25];12(Sup): 1819-29. Disponível em: www.scielo.br/pdf/csc/v12s0/05.pdf.

12. Veras CLSM, Vianna RPT. Desempenho de municípios paraibanos segundo avaliação de características da organização da atenção básica - 2005. Epidemiol Serv Saúde. 2009;18(2):133-40.

13 Saliba NA, Garbin CAS, Gonçalves PE, Santos JG, Souza NP, Moimaz SAS. Plano Municipal de Saúde: análise do instrumento de gestão. Biosci J. 2013;29(1):224-30.

14. Silva LAA, Bonacina DM, Andrade A, Oliveira TC. Desafios na construção de um projeto de educação permanente em saúde. Rev Enferm UFSM [Internet]. 2012 [acesso em 2012 nov 13];2(3):496-506. Disponível em: http://cascavel.ufsm.br/revistas/ojs-

2.2.2/index.php/reufsm/article/view/5364/pdf.

15. Vilasbôas ALQ. Prática de planejamento e implementação de políticas de saúde no âmbito municipal [tese]. Salvador: Universidade Federal da Bahia, Instituto de Saúde Coletiva; 2006. 129 p. 


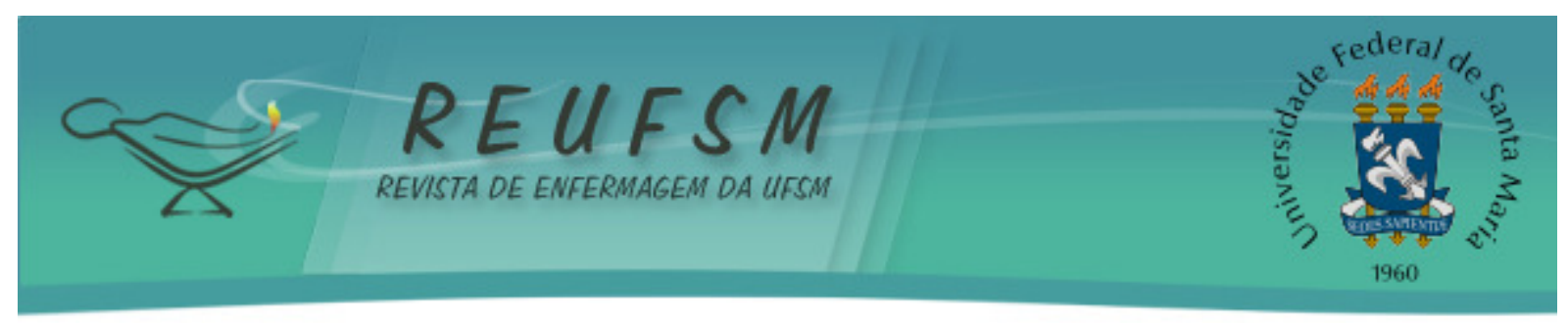

16. Cerqueira SCC. O processo de incorporação do plano municipal de saúde como tecnologia de gestão: o caso da Secretaria Municipal de Saúde de Salvador [dissertação]. Salvador: Universidade Federal da Bahia, Instituto de Saúde Coletiva; 2009. 202 p.

17. Mottin LM. Elaboração do plano municipal de saúde: desafio para o município. Um estudo no Rio Grande do Sul [dissertação]. Rio de Janeiro: Fundação Oswaldo Cruz, Escola Nacional de Saúde Pública; 1999. 156 p.

18. Lacerda JT, Calvo MCM, Berretta IQ, Ortiga AMB. Avaliação da gestão para o planejamento em saúde em municípios catarinenses. Ciênc Saúde Coletiva [Internet]. 2012 [acesso em 2012 out 29];17(4):851-59. Disponível em: http://www.scielosp.org/pdf/csc/v17n4/v17n4a08.pdf.

Data de recebimento: 22/01/2013

Data de aceite: 20/05/2013

Contato com autor responsável:

Endereço: Rua Guia Lopes, 1876, apto 04, Monte Alegre, Ribeirão Preto - SP

CEP: 14051-160

E-mail: caliopepilger@usp.br 